\title{
Developing Accelerated Stress Test Protocols for Solid Oxide Fuel Cells and Electrolysers: The European Project AD ASTRA
}

McPhail, S. J.; Pumiglia, D.; Laurencin, J.; Hagen, A.; Leon, A.; Van herle, J.; Vladikova, D.; Montinaro, D.; Piccardo, P.; Polverino, P.

Total number of authors:

11

Published in:

ECS Transactions

Link to article, DOI:

10.1149/09101.0563ecst

Publication date:

2019

Document Version

Peer reviewed version

Link back to DTU Orbit

Citation (APA):

McPhail, S. J., Pumiglia, D., Laurencin, J., Hagen, A., Leon, A., Van herle, J., Vladikova, D., Montinaro, D., Piccardo, P., Polverino, P., \& Herbrig, K. (2019). Developing Accelerated Stress Test Protocols for Solid Öxide Fuel Cells and Electrolysers: The European Project AD ASTRA. ECS Transactions, 91(1), 563-570. https://doi.org/10.1149/09101.0563ecst

\section{General rights}

Copyright and moral rights for the publications made accessible in the public portal are retained by the authors and/or other copyright owners and it is a condition of accessing publications that users recognise and abide by the legal requirements associated with these rights.

- Users may download and print one copy of any publication from the public portal for the purpose of private study or research.

- You may not further distribute the material or use it for any profit-making activity or commercial gain

- You may freely distribute the URL identifying the publication in the public portal 


\title{
Developing Accelerated Stress Test Protocols for Solid Oxide Fuel Cells and Electrolysers: the European project AD ASTRA
}

\author{
S.J. McPhaila, D. Pumigliaa, J. Laurencin ${ }^{\mathrm{b}}$, A. Hagen ${ }^{\mathrm{c}}$, A. Leon ${ }^{\mathrm{d}}$, J. Van Herle ${ }^{\mathrm{e}}$, D. \\ Vladikova $^{\mathrm{f}}$, D. Montinaro ${ }^{\mathrm{g}}$, P. Piccardo ${ }^{\mathrm{h}}$, P. Polverino ${ }^{\mathrm{i}}$, and K. Herbrig ${ }^{\mathrm{j}}$ \\ ${ }^{a}$ ENEA, Rome 00123, Italy \\ ${ }^{\mathrm{b}} \mathrm{CEA}$, Grenoble 38054, France \\ ${ }^{\mathrm{C}}$ DTU Energy, Roskilde 4000, Denmark \\ ${ }^{d}$ EIFER, Karlsruhe 76131, Germany \\ ${ }^{\mathrm{e}}$ EPFL, Sion 1951, Switzerland \\ fIEES, 1113 Sofia, Bulgaria

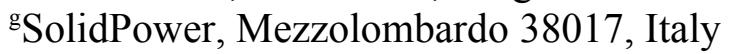 \\ hUniversity of Genoa, Genova 16145, Italy \\ iDept. of Industrial Engineering, University of Salerno, via Giovanni Paolo II 132, \\ Fisciano 84084, Italy \\ ${ }^{j}$ Sunfire, Dresden 01237, Germany
}

\begin{abstract}
In order to finally and systematically address the growing need for accelerated stress tests, given the longer lifetimes of solid oxide cells - both in fuel cell and electrolysis operation - the Fuel Cells and Hydrogen Joint Undertaking has launched an international initiative to overcome this epic challenge. The overall objective of the project that was awarded the task is the development of protocols that allow quantitative identification and prediction of critical degradation mechanisms, correlating them with overall performance variables in selected stack components (fuel electrode, oxygen electrode and interconnect). These will build firstly on the analysis of numerous field-tested samples of SOC stacks provided by the industrial partners, followed by applying existing and developing improved testing and modelling methods based on ex-situ component ageing and aggravated stack testing.
\end{abstract}

\section{Extended SOC lifetimes lead to increased need for accelerated testing}

Considering the useful lifetimes that are expected for commercial Solid Oxide Cell (SOC) stacks of up to 80000 hours (both for stationary CHP and energy storage applications), the current state-of-art durability is still a long way from meeting market requirements. Apart from more reliable system design, that provides better control and safeguard of the SOC stack during operation, the intrinsic degradation of the cell assembly still needs to be adequately addressed.

Even though a number of research institutions and companies have shown acceptable degradation rates of cells, stacks and systems for periods ranging from a few hundred to several thousand hours, neither reliable degradation models are currently available nor validated methodologies to evaluate expected stack durability in a practical timeframe. Thus any modification on material, cell or stack level, with the aim of increasing their 
durability, cannot bypass a (resource- and time-consuming) real-time durability test for verification of its effect. As increasing service times are being achieved, further development of more robust SOCs therefore calls urgently for accelerated lifetime tests, which enable rapid analysis of realistic degradation rates, and for degradation models that enable an extrapolation of realistic performance to system end of useful life.

Generally, a great number of operational parameters influence SOC degradation during lifetime, each contributing according to characteristic times and intensities, often in convoluted or even contrasting fashion. Aggravation of test input parameters (TIPs) can thus lead to non-representative accelerated degradation of a component where concurring effects are differently influenced, leading to a biased end state of the component investigated. For example, extensive studies on the effects on SOC positive electrodes of chromium evaporation from hot steel components have shown that aggravating different TIPs leads to diverging responses of the governing mechanisms (dissolution of $\mathrm{Cr}$ species in the perovskite phase, deposition and electrochemical volatilization of $\mathrm{Cr}$ species on active sites), see Figure 1 [1]. From the trends depicted in Figure 1, only varying current density could generate a coherent variation of the mechanisms (though the slight divergence of influences would need to be taken into account).
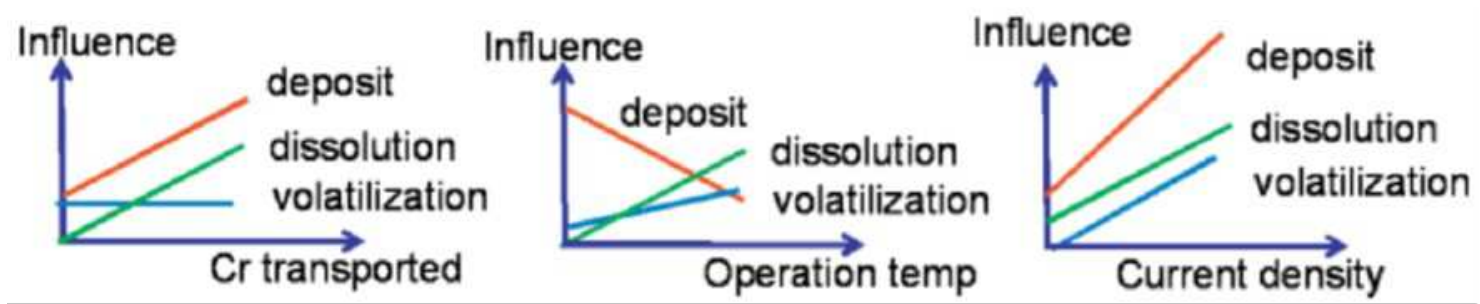

Figure 1: Influence of operating conditions on processes dominating $\mathrm{Cr}$-poisoning of SOFC cathodes [1]

Furthermore, the closely knit processes in a working SOC often lead to dominoeffects, whereby acute degradation occurring in one component or area can trigger or accelerate degradation elsewhere in the stack. Thus, it is crucial to identify the critical locations and dominant mechanisms that curtail SOC lifetime.

\section{AD ASTRA: a world-wide initiative to harness degradation mechanisms and validate accelerated testing protocols}

The Fuel Cells and Hydrogen Joint Undertaking (FCH JU), the public-private partnership in Europe that manages the European Commission's budget dedicated to the market deployment of fuel cell and hydrogen technologies, launched in 2018 a call for proposals to address the gaping need for validated accelerated stress test (AST) protocols. The team presenting this paper was successful in being awarded the mandate to work on this ever-challenging task, and under the short name of AD ASTRA (standing for "HArnessing Degradation mechanisms to prescribe Accelerated Stress Tests for the Realization of SOC lifetime prediction Algorithms") started operations on January $1^{\text {st }}$ 2019. 
The Call tendered for projects that would address both SOFC and SOEC operating modes. Whereas SOFC operation and possible accelerated ageing procedures have been extensively studied and attempted, respectively, capturing electrolysis degradation in short-term tests is radically innovative, since there are not even a significant number of stacks and systems in the field that have operated for more than 1 or 2 years consecutively.

The industrial partners in AD ASTRA (SOLIDPower and Sunfire) have among the most extensive records of SOC operation in the field, and world-class expertise on SOC manufacturing. This precious demonstration record and know-how - in both SOFC and SOEC operation - has led to the identification of three critical components limiting SOC stack lifetime:

- fuel (or negative) electrode

- oxygen (or positive) electrode

- interconnect

These critical areas were identified in the FCH JU project ENDURANCE [2], where a preliminary Failure Mode and Effects Analysis (FMEA) has been carried out, and by the SOC manufacturers through in-house FMEAs, all of which will serve as input to AD ASTRA. Furthermore, two types of applications will be considered that are most relevant for SOC systems:

- combined heat \& power generators (CHP)

- electrical energy storage into chemical energy (P2X)

The failure modes are different in dynamic and in stationary operation, both for electrolysis (which is relevant for P2X) and power generation (CHP). However, defects in the above mentioned components occur in both applications, and have been cited as critical by both participating industries (SOLIDpower for CHP, Sunfire for P2X), who will supply sufficient samples of SOC stacks and components operated in the real world to the research partners for analysis of the degradation effects and for benchmarking stacks and components tested in the accelerated stress conditions defined in AD ASTRA.

\section{International Collaboration}

Important initiatives on understanding and harnessing the critical degradation mechanisms in SOC stacks, and towards the developing of AST protocols for SOC, are undertaken also in Japan, South Korea and USA. The AD ASTRA project has engaged with recognized experts in this field, who will participate as External Advisors, as it is considered a global challenge to formulate reliable AST protocols for SOCs, for which a union of expertise and experience of the world-wide community is necessary. The External Advisors are:

- Prof. Hiroyuki Uchida, Director of the Clean Energy Research Center of Yamanashi University, leads the project "Research and Development of HighPerformance and Durable Electrodes for Reversible Solid Oxide Cells (HPDERSOC)" supported by funds for Advanced Low Carbon Technology Research and 
Development Program (ALCA) from Japan Science and Technology Agency (JST) [3-5].

- Prof. Xiao-Dong Zhou, formerly University of South Carolina now Lafayette University Louisiana, USA, runs the Department of Energy project "Developing Accelerated Test Protocols and tuning microstructures of common materials to improve SOFC robustness, reliability, endurance" [6], aiming to develop accelerated test protocols to establish common approaches for determining and projecting the durability of SOFC cathodes under simulated operating conditions $[7,8]$.

- Prof. Jong-Ho Lee, Principal Research Scientist at KIST, South Korea, running an important activity on Diagnosis and Suppression of SOC Air Electrode Degradation [9-13].

\section{Harnessing degradation: approach and methodology in AD ASTRA}

Although SOC stacks are being successfully integrated in increasingly mature market products, degradation phenomena and mechanisms affecting SOC performance and durability at stack level have not been completely identified nor satisfactorily addressed by the scientific community, which makes improvements on a sound knowledge foundation difficult and costly.

Accelerated testing is a crucial element of an efficient design-to-product chain. Long-term reliability of durable systems cannot be feasibly proven in real-time tests, so that protocols need to be defined that characterize the behaviour of a given product towards end-of-life in much shorter times. For SOC, techniques like adding contaminants to the reactants or tripping by sudden reoxidation and thermal cycles have been attempted, but these approaches do not comply with rigorous scientific method nor fully satisfy the current industrial needs: applying stressors to the whole stack can over- or under-accelerate irrelevant or relevant processes respectively, distorting the occurrence of degradation mechanisms and their compound effect on the stack performance (see Figure 1). This generates non-representative results, making vain the attempt to replicate a "normally" ageing stack and hindering the understanding of how the individual degradation mechanisms evolve over extended stack operation times. Conversely, isolating single components in order to restrict the occurring degradation mechanisms does not adequately represent the convoluted attack on the same component in the integrated stack environment. In either case, truthful correlation between these data and "real world" data is impeded.

To systematically address, harness and accelerate the failure modes of the 3 components that are the focus of AD ASTRA, a matrix will be set up of degradation mechanisms, test items, test procedures and characterization methods, that will be translated to protocols in such a way that consistent measurement data are generated. This will help subsequent analysis and correlation of phenomena and parameters by the modelling and simulation activities. A preliminary schematization for the 3 focus areas, with an indication of degradation effects in SOFC and SOEC modes, is given in Table 1. 
TABLE I. Preliminary mapping of failure modes and effects analysis for SOFC and SOEC with estimates for their criticality

\begin{tabular}{|c|c|c|c|c|c|}
\hline \multirow{2}{*}{ COMPONENT } & \multirow{2}{*}{ LOCATION } & \multicolumn{3}{|c|}{ OPERATIONAL DEGRADATION } & \multirow{2}{*}{$\begin{array}{l}\text { CRITICALITY } \\
\text { (1 low-5 high) }\end{array}$} \\
\hline & & Effect & SOFC MODE & SOEC MODE & \\
\hline \multirow{5}{*}{ Fuel Electrode } & Functional layer & Ni agglomeratín & Morphological instability & equal to SOFC & 4 \\
\hline & Functinal layer & Ni depletion & $\begin{array}{l}\text { Volatlization; loss of } \mathrm{Ni} \\
\text { percolation }\end{array}$ & equal to SOFC & 4 \\
\hline & Support & Reoxidation & $\begin{array}{l}\text { leakage @ seal interface due to } \\
\text { seal degradation }\end{array}$ & likely equal to SOFC & 2 \\
\hline & Support & Reoxidation & $\begin{array}{l}\text { leakage @ seal interface due to } \\
\text { thermal cycling mechanical stress }\end{array}$ & $\begin{array}{l}\text { unlikely due to litte thermal cycling } \\
\text { operation; }\end{array}$ & 2 \\
\hline & $\begin{array}{l}\text { Functinal } \\
\text { layer/electrolyte }\end{array}$ & Delaminatín & equal to SOEC & YSZ fragilisation & 2 \\
\hline \multirow{3}{*}{$\begin{array}{l}\text { Oxygen } \\
\text { Electrode }\end{array}$} & \begin{tabular}{|l|} 
Electrolyte \\
interface
\end{tabular} & Delaminatín & $\begin{array}{l}\text { insuffiient adhesion to } \\
\text { electrolyte }\end{array}$ & equal to SOFC & 4 \\
\hline & \begin{tabular}{|l} 
Electrolyte \\
interface
\end{tabular} & $\begin{array}{l}\text { Compositön } \\
\text { change }\end{array}$ & equal to SOEC & SrZrO3 formation & 3 \\
\hline & \begin{tabular}{|l} 
Electrolyte \\
interface
\end{tabular} & Cr poisoning & $\begin{array}{l}\text { Chromate deposits and } \\
\text { deactivates }\end{array}$ & likely equal to SOFC & 3 \\
\hline \multirow{8}{*}{ Interconnect } & \begin{tabular}{|l|} 
Air electrode \\
interface
\end{tabular} & Contact loss & corrosion & likely equal to SOFC & 3 \\
\hline & \begin{tabular}{|l} 
Air electrode \\
interface
\end{tabular} & Contact loss & material interdiffusion & likely equal to SOFC & 2 \\
\hline & $\begin{array}{l}\text { Air electrode } \\
\text { interface }\end{array}$ & Contact loss & spallation & likely equal to SOFC & 3 \\
\hline & $\begin{array}{l}\text { Air electrode } \\
\text { interface }\end{array}$ & Cr evaporation & Chromate volatlization & $\begin{array}{l}\text { likely equal to SOFC (similar gas } \\
\text { compositin at air side) }\end{array}$ & 3 \\
\hline & $\begin{array}{l}\text { Fuel electrode } \\
\text { interface }\end{array}$ & Contact loss & corrosion & $\begin{array}{l}\text { likely equal to SOFC (similar gas } \\
\text { composition but inverted in/out) }\end{array}$ & 2 \\
\hline & $\begin{array}{l}\text { Fuel electrode } \\
\text { interface }\end{array}$ & Contact loss & material interdiffusion & $\begin{array}{l}\text { likely equal to SOFC (similar gas } \\
\text { compositbon but inverted in/out) }\end{array}$ & 2 \\
\hline & $\begin{array}{l}\text { Fuel electrode } \\
\text { interface }\end{array}$ & Contact loss & spallation & $\begin{array}{l}\text { likely equal to SOFC (similar gas } \\
\text { composition but inverted in/out) }\end{array}$ & 2 \\
\hline & $\begin{array}{l}\text { Fuel electrode } \\
\text { interface }\end{array}$ & Cr evaporation & $\begin{array}{l}\text { Chromate volatlization but no } \\
\text { effect on fuel } \\
\text { electrode/electrolyte interface }\end{array}$ & likely equal to SOFC & 1 \\
\hline
\end{tabular}

The testing approach will consist of a dual-focus campaign targeting:

- macroscopic stack testing procedures, where short stacks will be operated in situ, in aggravated conditions with the objective of identifying test settings that will stress the stack in a representative way but minimizing testing time and resource expenditure

- specific component ageing tests, to reproduce (ex-situ) the degraded condition of critical stack components or interfaces in a faster time, based on analysis of the components extracted from stacks that have been field-tested.

Furthermore, a radical innovation will consist in the integration of these two methods: components specifically aged ex situ will be assembled into otherwise "new" stacks for in-situ testing, so that their effect on stack performance can be easily isolated from other components that in real-world conditions would also degrade. These tests allow to observe from the start $(\mathrm{t}=0)$ the end-of-service stack degradation, radically reducing insitu testing time and providing powerful means to validate models simulating the longterm effects of component degradation in a stack.

\section{Modelling of degradation and Remaining Useful Life (RUL) prediction}

In the literature many modelling works are available focusing on phenomena at microscale level. However, none of these currently manage to adequately capture the 
time-dependent deterioration of the governing processes. Continuous microscale models have been developed to take into account the electrode microstructural properties as well as the most likely processes occurring therein. In this approach, the reactive pathway is generally divided in a sequence of elementary reactions which are deterministically simulated, thereby preserving physical representativeness but costing enormous computing effort and time.

On the other hand, different, higher-level modelling approaches (lumped, 1-D or black-box modelling) are being investigated, that allow faster assessment of the complex phenomena causing macroscopic performance degradation. This approach helps linking the main variables affecting degradation for the definition of suitable control strategies and provides the modelling basis on which degradation models and, thus, lifetime prediction tools for performance model can be built.It is worth observing, furthermore, that only few works include the dependence of SOC performance on degradation mechanisms by means of simplified modelling approaches, which guarantee computational time compatible with lifetime predictions.

In AD ASTRA, a real attempt will be made towards integrating degradation and RUL prediction in performance models. Inorder to concretize the understanding of the physical degradation mechanisms, a multi-scale numerical tool will be adapted and optimized, combining two electrode-scale models with a macroscopic two-dimensional cell approach developed by CEA $[14,15]$. The macro-model enables to take into account the flow configuration of the stack and it allows determining the distribution of local parameters along the cell radius, such as the gas concentration, the current density, the ohmic losses or the electrode concentration and activation overpotentials.

To assist and simplify the physical modelling, considerable efforts will be devoted in AD ASTRA to the representation of physical degradation mechanisms through mathematical models (either statistic or first principle based) to represent the evolution of the most representative parameters. Then the best grey-box dynamic modelling approaches (i.e. based on Ordinary Differential Equations) will be selected among, for example, first principle macro balances, lumped parameters or statistical models.

In order to take into account the spatial distribution of SOC parameters, such as materials, geometry, production processes etc., a statistical approach will be adopted to model the time-evolution of degradation parameters. The main outcome will be a set of fast models describing the time evolution of parameters representing each selected degradation phenomenon as a function of operation as well [38], allowing to estimate the SOC performance and lifetime (RUL) as function of operation severity.

The whole modelling scheme is represented in Fig. 2, which summarizes the approach from physical degradation analysis/models at component level towards performance and lifetime models at stack level. 


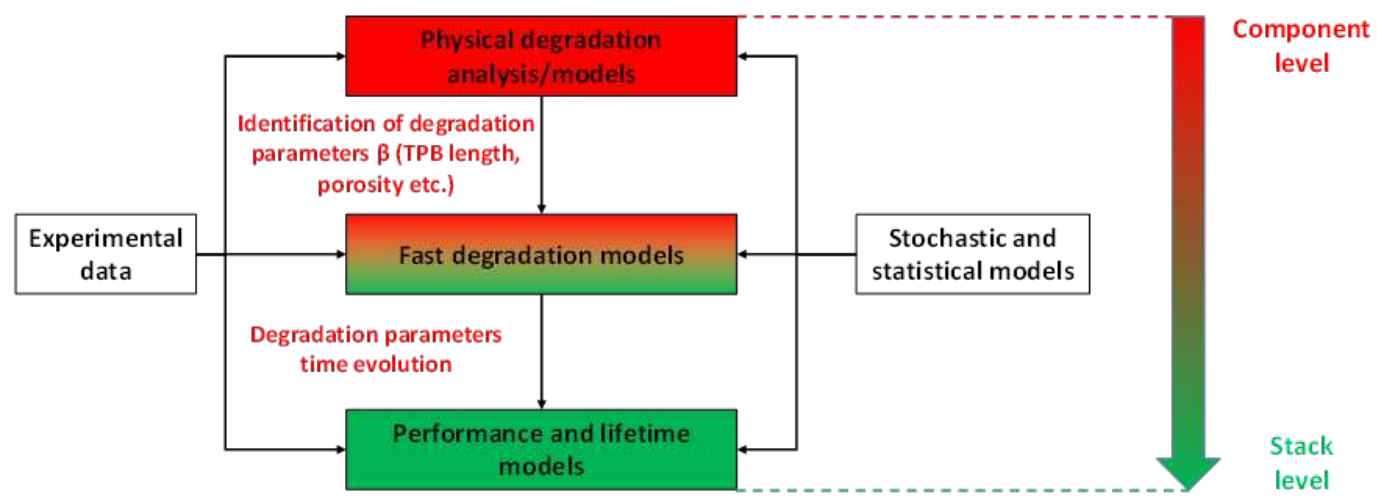

Figure 2: AD ASTRA Modelling scheme from physical degradation analysis/models at component level toward performance and lifetime models at stack level

\section{Transferring practice to procedures}

In order to maximize the uptake and impact of the systematic work carried out in AD ASTRA, the experimental experience will be synthesized into applicable, as much as possible generally validprocedures that will be submitted for standardization. Based on experience in key FCH JU projects such as SOCTESQA, ENDURANCE, INSIGHT, IDFAST, AD ASTRA will fit its findings to integrate effectively with procedures developed there. Furthermore, various participants in the project are members of the RSC Strategy Coordination Group of FCH JU2, as well as of the Working group on Harmonization of testing protocols for stationary applicationswithin FCH JU projects, initiated by the Joint Research Centre (JRC) in November 2016. AD ASTRA will contribute to this Working Group, as well as liaise with the International Electrotechnical Commission (IEC), in particular with Technical Committee 105 on Fuel Cells, taking into account Technical Specification 62282-7-2 on SOFC testing and the International Standard under development 62282-8-101 on reversible SOC testing, to promote continuation of the AST protocol standardization for international benefit.

\section{Conclusions}

A momentous task has been undertaken by the European project AD ASTRA, to get to the core of SOC degradation mechanisms in fuel cell and electrolysis modes, with the objective to conceive, test and validate experimental procedures for accelerated ageing of critical SOC components. International collaboration in this objective is of paramount importance to ultimately define widely applicable, comprehensive approaches to controlled ageing of SOC components, which will also help to develop degradation correlations for deterministic models as well as for fast, stochastic-based models for the prediction in operand of remaining useful lifetime. 


\section{Acknowledgments}

This project has received funding from the Fuel Cells and Hydrogen Joint Undertaking under Grant Agreement No 825027. This Joint Undertaking receives support from the European Union's Horizon 2020 research and innovation program and Hydrogen Europe.

\section{References}

1. H. Yokokawa, T. Horita, K. Yamaji, H. Kishimoto, T. Yamamoto, M. Yoshikawa, Y. Mugikura, K. Tomida, Fuel Cells,13 (2013)

2. http://www.durablepower.eu/

3. K. Shimura, H. Nishino, K. Kakinuma, M.E. Brito, H. Uchida, J. CERAM. SOC. JPN 125 (4) (2017)

4. P. Puengjinda, H. Nishino, K. Kakinuma, M.E. Brito, H. Uchida, J. Electrochem. Soc., 164 (9) (2017)

5. H. Uchida, P. Puengjinda, K. Shimura, H. Nishino, K. Kakinuma, M.E. Brito, ECS Trans. 8 (1) (2017)

6. https://www.netl.doe.gov/research/coal/project-information/proj?k=FE0026097

7. E. Dogdibegovic, N.S. Alabri, C.J. Wright, J.S. Hardy, C.A. Coyle, S.A. Horlick, W. Guan, J.W. Stevenson, X-D. Zhou, J. Electrochem. Soc., 164(12) (2017)

8. E. Dogdibegovic, J. Yan, Q. Cai, H. Young, Z. Xing, Z. Liu, R.W. Goettler, X-D. Zhou, J. Electrochem. Soc., 164(10) (2017)

9. J.-H. Lee, H. Kim, K.J. Yoon, M. Park, H. Kim, J. Son, B. Kim, H. Lee, ECS Trans. (2017)

10. S.K. Jaiswal, J. Hong, K.J. Yoon, J.W. Son, J.H. Lee, J. Am. Ceram. Soc. 100 (2017)

11. H. Kim, S.H. Choi, J. Kim, H.W. Lee, H. Song, J.H. Lee, J. Mater. Process. Technol. 210 (2010)

12. H.G. Jung, Y.K. Sun, H.Y. Jung, J.S. Park, H.R. Kim, G.H. Kim, H.W. Lee, J.H. Lee, Solid State Ion. 179 (2008)

13. J.H. Song, S. Il Park, J.H. Lee, H.S. Kim, J. Mater. Process. Technol. 198 (2008)

14. J. Laurencin, D. Kane, G. Delette, J. Deseure, F. Lefebvre-Joud, J. Power Sources 196 (2011)

15. M. Guida, F. Postiglione., G. Pulcini, 5th International Conference on Engineering Failure Analysis (ICEFA 2012), Den Haag (Holland). 